\title{
Evaluation of Intra-examiner Variability in Video Head Impulse Test Results
}

\author{
Başak Mutlu, PhD ${ }^{1}$ Sıdıka Cesur, PhD ${ }^{2}$ Merve Torun Topçu, MSc ${ }^{1}$ Cennet Reyyan Geçici, MSc ${ }^{2}$ \\ Öyküm Esra Așkın, PhD ${ }^{30}$ Emine Ufuk Derinsu, $\mathrm{PhD}^{2}$
}

${ }^{1}$ Department of Audiology, School of Health Sciences, Istanbul Medeniyet University, Istanbul, Turkey

2 Department of Otorhinolaryngology, Subdepartment of Audiology, School of Medicine, Marmara University, Istanbul, Turkey

${ }^{3}$ Department of Statistics, Yıldız Faculty of Arts and Sciences, Istanbul Technical University, Istanbul, Turkey

J Am Acad Audiol 2020;31:613-619.
Address for correspondence Başak Mutlu, PhD,

basak.mutlu@medeniyet.edu.tr.

\begin{abstract}
Keywords

- video head impulse test

- inter-examiner variability

- vestibulo-ocular reflex gain

Objective The video head impulse test (vHIT) is a diagnostic tool to assess the function of the semicircular canals and branches of the vestibular nerve. The aim of this study was to analyze the inter-examiner variability of vHIT results in healthy subjects. Materials and Methods A total of 21 healthy participants were included in the study. vHIT responses were collected by four clinicians. Variability of the vHIT results between examiners was analyzed statistically.

Results The vestibulo-ocular reflex (VOR) velocity regression values were from 0.99 to 1.09 degrees per second for the lateral canals. For the vertical canals, VOR velocity regression values were from 0.87 to 1.21 degrees per second. According to repeated measures analysis of variance, the normality assumptions for the velocity regression of the left lateral canal $(p=0.002)$ and the right anterior canal $(p<0.01)$ were met and the differences were statistically significant. The normality assumptions were not met for 40,60 , and 80 ms median gain of the right lateral canal $(p=0.016, p=0.038$, and $p=0.001$, respectively); 40 and 60 ms median gain of the left lateral canal $(p<0.001$ and $p=0.008$, respectively); and the velocity regression of the left posterior canal $(p<0.00)$. These differences were found to be statistically significant by using the Friedman test.

Conclusion The inter-examiner differences of the VOR gain values for the VHIT were statistically significant. Serial vHIT testing should be performed by the same examiner to reduce the effects of inter-examiner variability.
\end{abstract}

The prevalence of dizziness in the general population is between 20 and $56 \% .^{1-3}$ There are many bedside and laboratory tests used for evaluation of the vestibular function. The bithermal caloric test, rotational chair, and video head impulse test (vHIT) are the most widely used tests for the evaluation of semicircular canals. ${ }^{4,5}$ Recently, vHIT appears to be a very good screening test for verifying the vestibuloocular reflex (VOR) gain and allowing fast, simple, and accurate assessment of functional status of each of the six semicircular canals individually. The gain of VOR is defined as the ratio of slow phase compensatory eye velocity to head impulse velocity. VOR produces eye movements in the direction opposite to head movement and equal in amplitude. When the head is moved laterally right or left, the endolymph in the vestibular organ will move to the opposite direction as well. This movement induces a deflection of the received

March 6, 2019

accepted after revision

February 22, 2020

published online

October 20, 2020
Copyright $\odot 2020$ by the American

Academy of Audiology. All rights reserved. Thieme Medical Publishers, Inc., 333 Seventh Avenue, New York, NY 10001, USA.

Tel: +1(212) 760-0888.
DOI https://doi.org/ 10.1055/s-0040-1717124. ISSN 1050-0545. 
cupula whereby the stereocilia bend toward the kinocilium. As a result of this movement, activity of agonist primer afferent neurons increases and activity of antagonist primer afferent neurons decreases simultaneously. These excitatory and inhibitory activities in the afferent fibers are transmitted to the vestibular nuclei. The excitatory signals are transferred to the oculomotor nuclei from here, stimulating the contralateral lateral rectus and the ipsilateral medial rectus muscles. The inhibitory projections are sent to the antagonist oculomotor neurons. This extraocular muscle activity results in eye movement toward the opposite direction. ${ }^{6-9}$

When the head is moved vertically vertical VOR occurs. The excitatory afferents from the anterior semicircular canals synapse in the superior vestibular nucleus (SVN). Their excitatory signals activate the ipsilateral superior rectus (SR) and contralateral inferior oblique (IO) muscles. Their inhibitory signals are relayed to the ipsilateral trochlear nucleus, which innervates the contralateral superior oblique (SO) muscle, and to the ipsilateral oculomotor subnucleus that innervates the ipsilateral inferior rectus (IR) muscle. The excitatory afferents from the posterior semicircular canals synapse in the medial vestibular nucleus (MNV). Their signals stimulate the ipsilateral SO muscle, and the contralateral IR muscle. The inhibitory afferents from the posterior semicircular canals activate the ipsilateral IO and contralateral SR muscles. $^{6-9}$

If VOR is normal, eyes can maintain visual fixation on a steady target despite head movements. In case of vestibular hypofunction, VOR is impaired with gain and appearance of refixation saccades. ${ }^{6,7,10-14}$ In that the VOR gain for each ear can be an important indicator of vestibular impairment. However, vHIT technique has some limitations which are based on the ability of the examiner to perform reliable, quick, and succinct head rotations. vHIT requires the examiner who performs the head movement to have sufficient skills and the subject to have adequate neck mobility to avoid potential injury. ${ }^{15}$ However, sometimes it is not possible to give appropriate and correct impulse to the patient. In some cases, inability of subjects to release their cervical muscles or tend to participate actively in the test may impair the accuracy of the stimulation. Moreover, sometimes artifacts may occur due to contact with the glasses during head movements. Studies have shown that VOR gain is influenced by the examiner, hand position, and goggle slip-

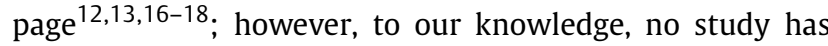
attempted to compare the results obtained by more than two clinicians using the same vHIT device and the same hand position for all canals. Therefore, in this study we aimed to determine whether the VOR gain results of the same subject obtained by four examiners varied in the VHIT test.

\section{Materials and Methods}

The protocol was approved by the University Clinical Researches Ethical Committee (No: 09.2017.617), and written informed consent was obtained from each subject. A total of 21 healthy adult volunteer participated in the study. All participants presented with normal hearing and negative history of vestibular or neurological disease and cervical spine injury. vHIT responses were collected by four clinicians. All examiners had approximately 1 year vHIT experience levels. Except examiner 3, all examiners were right-handed. The monocular EyeSeeCam video-oculography (EyeSeeCam, Munich, Germany) system was used for recording the vHIT responses. The camera was positioned to enable left-eye velocity recording. Prior to test, each participant was seated to a stable chair and instructed to relax his or her neck and fixate on the target. Participants were seated facing the wall at a distance of 5 feet. A little sticker as the visual target was fixed to the wall at 4 feet above the floor at the central gaze. The goggles were fixed using an elastic band to each participant's head that could be tightened or loosened to ensure that there was no goggle slippage. The camera position was adjusted so that the pupil was centered on the video display to ensure that the eye would be accurately tracked with head movements. Calibration of the EyeSeeCam was performed using a laser affixed to the center of the goggles. The calibration procedure was completed in the same room lighting conditions with vHIT. Before the test, each examiner repeated head and eye calibrations for each participant. Examiners removed the goggles in-between testing. The head movement calibration was repeated prior to collecting vertical canal calibration. All examiners used same hand placement technique to elicit the vHIT responses. Hands were placed on the chin (i.e., coupling the chin and jaw), and the subject was instructed to clench the jaw during horizontal canal impulses. During vertical canal test examiners changed their hand positions. The participant heads moved in the plane of the canals while directly facing the target. The examiner placed his dominant hand on the top of the head and the other hand beneath the chin. The examiner stood behind the participant (-Fig. 1). The examiners were cognizant not to contact goggles or the strap of the goggle during the test to prevent artefacts. All six semicircular canals were evaluated. Head impulses were conducted from the back of the subject to each side with unpredictable and abrupt timing and direction. During the test of horizontal canals, the head was pitched downward nearly 30 degrees and then stimulus was delivered. During vertical canals test, stimulus was delivered diagonal head pitch forward and backward to activate vertical canals. At least 12 to 20 impulses were recorded for each direction. The velocity of the head rotation was targeted between 150 and 300 degrees per second with an amplitude of 5 to 20 degrees. $^{19}$ For lateral canal quantitative comparisons, the instantaneous VOR gains at 40,60 , and $80 \mathrm{~ms}$, VOR velocity regression, and gain asymmetries were recorded. For vertical canals only VOR velocity regressions were analyzed. Since all subjects recruited in this study were healthy controls, the VOR gain should hypothetically be nearly 1 . Saccadic eye movement or abnormally low (< 0.79 ) VOR gain was interpreted as a possible error. ${ }^{10}$ There were no saccadic eye movements in subjects but abnormally low VOR gains were recorded. In those situations the test was repeated. Breaks were offered to the participants throughout testing to minimize excessive blinks and fatigue. 


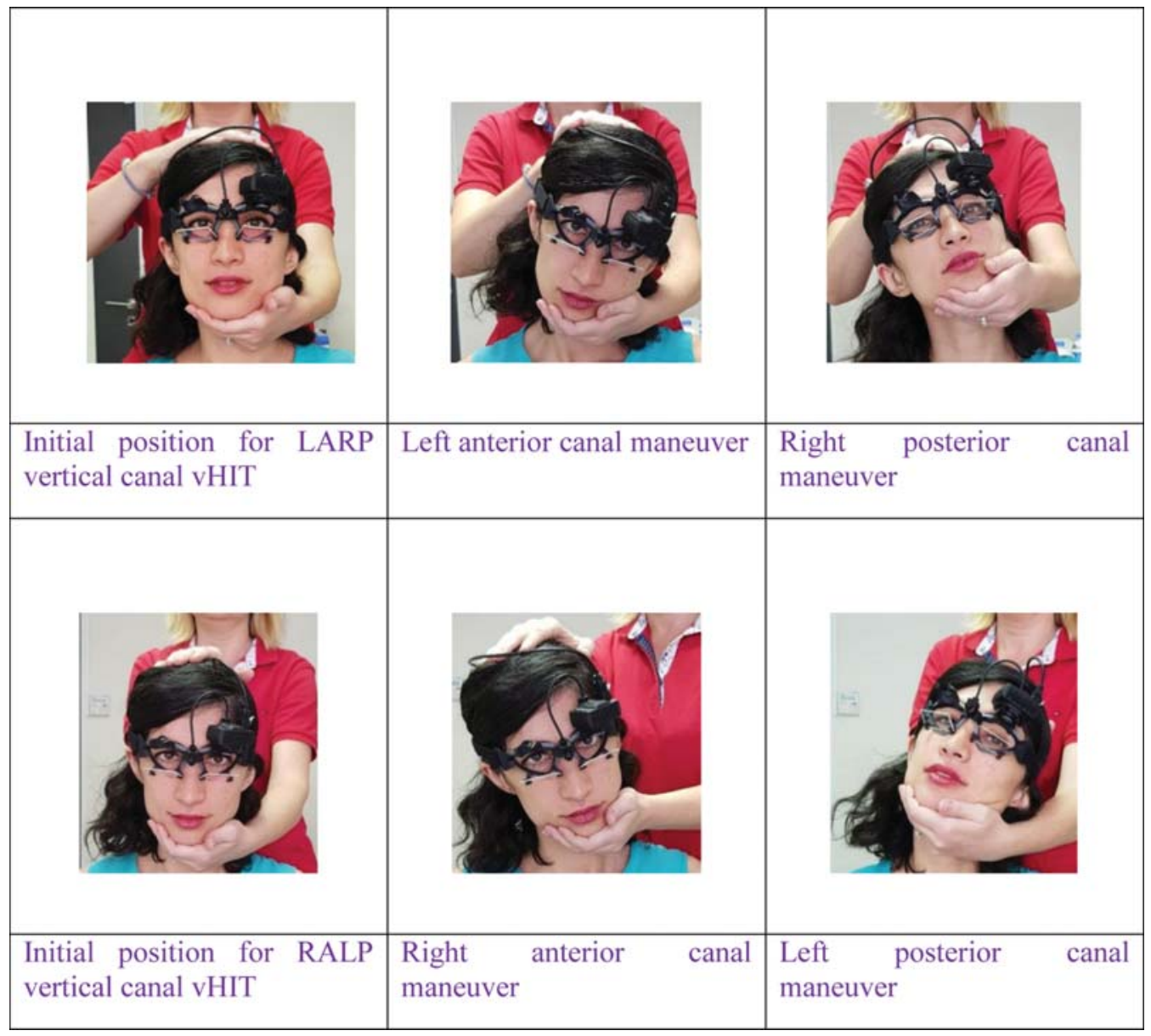

Fig. 1 Visualization of the video head impulse test (vHIT) test procedures for vertical canals.

The criterion for a normal interocular VOR gain asymmetry was that it should be between 0 and $13.3 \%$ for all canals. ${ }^{19}$ Blödow et al defined an abnormal gain asymmetry $>8.5 \%$ as the outside of mean \pm 2 standard deviations (SDs) which was found in 30 normal subjects in their laboratory. ${ }^{20}$ All testing took less than 30 minutes for each participant. A break of 10 minutes was provided between each examiner. Order of examiners was random.

\section{Statistical Analysis}

Descriptive statistics were used to describe the sample age and the vHIT results of six semicircular canals (gains and velocities). To establish the inter-examiner reliability, intraclass correlation coefficients (ICCs; two-way random model with absolute agreement) with 95\% confidence intervals were used to determine inter-rater reliability. Based on the 95\% confidence interval of the ICC estimate, values lower than 0.5 , between 0.5 and 0.75 , between 0.75 and 0.9 , and greater than 0.90 were indicative of poor, moderate, good, and excellent reliability, respectively. ${ }^{21}$ To test the differences between the four examiners and their measurements, repeated measures analysis of variance (ANOVA) and Friedman tests were performed using Greenhouse-Geisser adjustment. The adjustment of Greenhouse-Geisser was utilized in cases where the sphericity assumption was violated in repeated measures ANOVA. The Friedman test is a nonparametric alternative of the repeated measures ANOVA, and both procedures were used when all subjects in a study were measured under different conditions. In this study, the vHIT of six canals was administered to 21 subjects, and each test was measured by four different examiners. For quantitative comparisons, for lateral canals, the instantaneous VOR gains at 40,60, and $80 \mathrm{~ms}$, velocity regressions, and gain asymmetries were analyzed. For vertical canals only velocity regressions were analyzed. The Shapiro-Wilk normality test was used to assess the normality of the distribution for each finding, and it was decided which statistical test should be applied among parametric or nonparametric ones. The Friedman test was used if at least one test measured by any examiner did not follow normal distribution. After finding an existence of significant difference between examiners, post hoc pair-wise comparison or Mann-Whitney $U$ tests were utilized to identify which examiners were different from the others.

\section{Results}

A total of 21 healthy participants (male: 10 ; female: 11 ), aged $\geq 17$ years (mean \pm SD age: $26.04 \pm 6.2$ years) were included in the study. - Table 1 presents the vHIT recordings of all six canals. For lateral canals, the VOR velocity regression values were from 0.99 to 1.09 degrees per second. Note that 40,60 , 
Table 1 vHIT findings of the participants for all six semicircular canals (mean \pm standard deviation)

\begin{tabular}{|c|c|c|c|c|c|c|}
\hline & vHIT parameters & Examiner 1 & & Examiner 2 & Examiner 3 & Examiner 4 \\
\hline \multirow[t]{9}{*}{ Lateral canals } & \multirow[t]{3}{*}{ Velocity regression } & Right $(\% / \mathrm{sec})$ & $1.02 \pm 0.1$ & $1 \pm 0.1$ & $1.02 \pm 0.1$ & $0.99 \pm 0.1$ \\
\hline & & Left $\left({ }^{\circ} / \mathrm{sec}\right)$ & $1.09 \pm 0.1$ & $1.05 \pm 0.1$ & $1.05 \pm 0.1$ & $0.99 \pm 0.1$ \\
\hline & & Gain asymmetry (\%) & $4.2 \pm 2.5$ & $3.1 \pm 2.6$ & $2.76 \pm 2.6$ & $2.62 \pm 2.8$ \\
\hline & \multirow[t]{2}{*}{$40 \mathrm{~ms}$ median gain $\left({ }^{\circ} / \mathrm{sec}\right)$} & Right & $1.11 \pm 0.3$ & $1.07 \pm 0.1$ & $1.22 \pm 0.3$ & $1.06 \pm 0.2$ \\
\hline & & Left & $1.1 \pm 0.3$ & $0.98 \pm 0.1$ & $1.02 \pm 0.1$ & $0.96 \pm 0.1$ \\
\hline & \multirow[t]{2}{*}{$60 \mathrm{~ms}$ median gain $\left({ }^{\circ} / \mathrm{sec}\right)$} & Right & $0.96 \pm 0.1$ & $0.96 \pm 0.1$ & $0.92 \pm 0.1$ & $0.93 \pm 0.1$ \\
\hline & & Left & $1.01 \pm 0.2$ & $1.02 \pm 0.1$ & $1.08 \pm 0.1$ & $1 \pm 0.1$ \\
\hline & \multirow[t]{2}{*}{80 ms median gain ( $/ \mathrm{sec})$} & Right & $0.86 \pm 0.1$ & $1.17 \pm 0.1$ & $1.22 \pm 0.2$ & $1.06 \pm 0.25$ \\
\hline & & Left & $0.93 \pm 0.1$ & $1.07 \pm 0.1$ & $1.07 \pm 0.1$ & $0.96 \pm 0.1$ \\
\hline \multirow[t]{4}{*}{ Vertical canals } & \multirow[t]{4}{*}{ Velocity regression $(\% / \mathrm{sec})$} & Right anterior & $1.21 \pm 0.2$ & $1.01 \pm 0.1$ & $1.02 \pm 0.2$ & $1.02 \pm 0.2$ \\
\hline & & Left posterior & $1.07 \pm 0.1$ & $0.87 \pm 0.1$ & $0.88 \pm 0.1$ & $0.95 \pm 0.3$ \\
\hline & & Right posterior & $1.16 \pm 0.2$ & $1.15 \pm 0.2$ & $1.1 \pm 0.2$ & $1.11 \pm 0.2$ \\
\hline & & Left anterior & $1.12 \pm 0.2$ & $1.08 \pm 0.2$ & $1.05 \pm 0.1$ & $1.08 \pm 0.2$ \\
\hline
\end{tabular}

Abbreviation: vHIT, video head impulse test.

and $80 \mathrm{~ms}$ instantaneous median gain values were from 0.96 to 1.22 degrees per second, from 0.92 to 1.08 degrees per second, and from 0.86 to 1.22 degrees per second, respectively, and the interocular gain asymmetry values were from 2.62 to $4.2 \%$ among examiners. For vertical canals, the VOR velocity regression values were from 0.87 to 1.21 degrees per second. Interocular gain asymmetry values for right anterior-left posterior (RALP) were from 5.29 to $8.76 \%$ and for left anterior-right posterior (LARP) from 5.4 to 8.85\% among examiners.

The inter-examiner reliability was evaluated using the ICC (-Table 2). The lowest and the highest ICC values were -0.003 (the gain asymmetry of the lateral canal) and 0.841
(40 ms instantaneous median gain of the left lateral canal), respectively.

According to the Shapiro-Wilk test, the normality assumptions for the velocity regression of the left lateral canal ( $p_{\text {examiner }} 1=0.077, p_{\text {examiner }} 2=0.754, p_{\text {examiner }}$ $3=0.677, p_{\text {examiner }} 4=0.367$ ) and the right anterior canal ( $p_{\text {examiner } 1}=0.588, p_{\text {examiner } 2}=0.639, p_{\text {examiner } 3}=0.098$, $p_{\text {examiner } 4}=0.768$ ) were met and the differences were found as statistically significant in repeated measures ANOVA. For the left lateral canal, the pair-wise comparisons of the velocity regression indicated that the differences between the measurements of examiners 1 and $4(p=0.002)$ and examiners 2 and $4(p=0.012)$ were statistically significant.

Table 2 Inter-examiner correlation coefficients

\begin{tabular}{|c|c|c|c|c|}
\hline & \multirow[t]{2}{*}{ Test } & & \multicolumn{2}{|c|}{ Inter-examiner ICC Values } \\
\hline & & & Mean \pm SD; range & ICC \\
\hline \multirow[t]{9}{*}{ Lateral canals } & \multirow[t]{3}{*}{ Velocity regression } & Right & $1.01 \pm 0.1 ; 0.03$ & 0.815 \\
\hline & & Left & $1.05 \pm 0.1 ; 0.1$ & 0.594 \\
\hline & & Gain asymmetry & $3.17 \pm 2.7 ; 1.6$ & -0.003 \\
\hline & \multirow[t]{2}{*}{40 ms median gain } & Right & $1.12 \pm 0.2 ; 0.16$ & 0.838 \\
\hline & & Left & $1.12 \pm 0.2 ; 0.16$ & 0.841 \\
\hline & \multirow[t]{2}{*}{60 ms median gain } & Right & $0.98 \pm 0.1 ; 0.07$ & 0.727 \\
\hline & & Left & $1.02 \pm 0.1 ; 0.1$ & 0.461 \\
\hline & \multirow[t]{2}{*}{80 ms median gain } & Right & $0.92 \pm 0.1 ; 0.097$ & 0.705 \\
\hline & & Left & $0.95 \pm 0.1 ; 0.04$ & 0.624 \\
\hline \multirow[t]{4}{*}{ Vertical canals } & \multirow[t]{4}{*}{ Velocity regression } & Right anterior & $1.06 \pm 0.2 ; 0.19$ & 0.444 \\
\hline & & Left posterior & $0.94 \pm 0.2 ; 0.42$ & -0.116 \\
\hline & & Right posterior & $1.13 \pm 0.2 ; 0.06$ & 0.642 \\
\hline & & Left anterior & $1.08 \pm 0.2 ; 0.07$ & 0.532 \\
\hline
\end{tabular}

Abbreviations: ICC, intraclass correlation coefficients; SD, standard deviation. 
Similarly, for the right anterior canal, the pair-wise comparisons of the velocity regression indicated that the differences between the measurements of examiner 1 and all other examiners $(p<0.001)$ were statistically significant at $95 \%$ confidence level.

The normality assumptions were not satisfied for 40,60 , and $80 \mathrm{~ms}$ median gain of the right lateral canal; 40 and $60 \mathrm{~ms}$ median gain of the left lateral canal; and the velocity regression of the left posterior canal (all $p$-values of examiners are less than 0.05). Friedman test was used due to the nonnormal behavior of the above-mentioned data sets and it was found that the differences between operators were statistically significant for 40,60 , and $80 \mathrm{~ms}$ median gain of the right lateral canal $(p=0.016, p=0.038$, and $p=0.001$, respectively), 40 and $60 \mathrm{~ms}$ median gain of the left lateral canal ( $p<0.001$ and $p=0.008$, respectively), and the velocity regression of the left posterior canal $(p<0.001)$. The difference between the measurements of the examiners is shown in the column titled "Differences of Operators" in - Table 3.

The importance of effect size has been increasingly recognized as an index that indicates how significant or negligible the results of the study are to be considered regardless of the sample size. After performing parametric and nonparametric tests for the purpose of whether there is a significant difference between measurements of four examiners, the question of how significant is that difference arises. To put forth the degree of association between the main effect and dependent variable (i.e., vHIT responses of examiners), the values of effect sizes were also reported in the last column of - Table 3. When the repeated measures ANOVA and Friedman tests were utilized, effect sizes were specified by partial eta-squared and Kendall's W, respectively. According to the Cohen's interpretation of effect sizes, moderate effects were detected for $40 \mathrm{~ms}$ median gain of the left lateral canal, velocity regression of the right anterior canal, and velocity regression of left posterior canal.

\section{Discussion}

The objective of this study was to investigate the inter-examiner variability of vHIT results in healthy subjects. In this study, VOR velocity regression values of all six canals and the instantaneous median gains at 40,60 , and $80 \mathrm{~ms}$ of the lateral canals were analyzed. The gain asymmetry of the lateral canals was added to the parameters because the gain asymmetry for the vertical canals is a parameter with poor consistency. In some studies using vHIT, VOR velocity regressions ranged from 0.95 to 0.99 degrees per second in the lateral canals ${ }^{22-25}$ and from 0.9 to 0.98 degrees per second in the vertical canals ${ }^{25}$ for healthy participants. The instantaneous median gains for 40 , 60 , and $80 \mathrm{~ms}$ were $1.02 \pm 0.13$ degrees per second, ${ }^{22}$ from 0.86 to 0.95 degrees per second, ${ }^{25}$ and $0.89 \pm 0.07$ degrees per second, ${ }^{22}$ respectively. Similarly, in the current study, it was observed that the mean value for velocity regression values ranged from 0.91 to 1.12 degrees per second in the lateral canals and from 0.9 to 1.21 degrees per second in the vertical canals; moreover, at 40,60, and $80 \mathrm{~ms}$, instantaneous median gain values of the lateral canals range from 0.96 to
1.22 degrees per second, 0.92 to 1.08 degrees per second, and 0.86 to 1.17 degrees per second, respectively. The gain asymmetry values obtained in our study were from 2.62 to $4.2 \%$ for lateral canals, from 5.29 to $8.76 \%$ for RALP, and from 5.4 to $8.85 \%$ for LARP. Our results are compatible with the values presented in previous studies: $3.7 \% \pm 2.8 \%,{ }^{26} 4 \% \pm 1 \%,{ }^{27}$ and $4 \% \pm 3.2 \%{ }^{25}$ for lateral canals. We found that the mean velocity regression values for both, the lateral and vertical canals, were similar to each other, with no significant difference between the right and left side values. There was no significant difference between the lateral and vertical canal VOR gains on both sides. Some studies similar to the present study have reported that there was a higher VOR gain for the lateral canal than for the vertical canals. ${ }^{28-30}$ Other trials have stated that the right lateral and vertical canal VOR gains were significantly higher than the left canal VOR gains. ${ }^{17,28,29}$ In the current study, the left posterior canal velocity regression values were slightly lower (however not statistically different) than that for other vertical canals. This result may be attributable to both the left eye location of the camera and the left posterior maneuver being slightly more difficult for right-handed clinicians.

When inter-examiner ICCs were examined, we found that the lateral canal correlation coefficients were higher than those for the vertical canals. Thus, the lateral canals parameters showed greater consistency between the examiners. It is well known that vertical head impulses are more challenging to deliver than horizontal impulses because the planes of the vertical canals lie diagonally in the head, and the neck movements along those diagonal planes are awkward to deliver and uncomfortable for the subject. These findings may be attributable to the anatomical position of the lateral canals and easier excitation by the examiner. ${ }^{12,13}$

According to statistical analysis, significant differences were found among the examiners in most test parameters of lateral and vertical canals. There was a significant difference between the examiners for the instantaneous median gains of the lateral canals at 40,60 , and $80 \mathrm{~ms}$. On the other hand, the velocity regression values of the right lateral, right posterior, and left anterior vertical canals among the examiners were similar.

This study was performed by four different examiners, of which, three had right-hand dominance and one had left-hand dominance. When the differences between the inter-examiner test results were examined, the variation in results of the examiner with the left-hand dominance and those with righthand dominance were similar to other intra-examiner differences. The fact that the differentiation among the examiners is almost evenly distributed indicates that hand dominance is not an important factor that influences the results and affects the difference between the examiners. However, this finding is insufficient to establish a definite conclusion. Therefore, further studies should investigate this variable more extensively, with more number of examiners and a greater sample size of subjects with vestibular disorders.

vHIT is a valuable and objective tool to especially diagnose peripheral vestibular pathologies. However, it is a technically challenging test for the clinician. Thus, this test needs skillful and experienced clinician. In the literature, it is stated that 
Table 3 Analysis of variance and Friedman tests results

\begin{tabular}{|c|c|c|c|c|c|c|c|c|c|}
\hline & \multirow{2}{*}{$\begin{array}{l}\text { Test } \\
\text { number }\end{array}$} & & \multirow{2}{*}{$\begin{array}{l}\text { Tests of } \\
\text { within- } \\
\text { subjects } \\
\text { effects } \\
\text { F-value }\end{array}$} & \multicolumn{2}{|l|}{ Decision } & \multirow{2}{*}{$\begin{array}{l}\text { Differences of } \\
\text { operators }\end{array}$} & \multicolumn{2}{|c|}{ Significance } & \multirow{2}{*}{$\begin{array}{l}\text { Effect } \\
\text { size }\end{array}$} \\
\hline & & & & $\begin{array}{l}\text { Chi-square } \\
\text { value }\end{array}$ & Significance & & & & \\
\hline \multirow[t]{9}{*}{$\begin{array}{l}\text { Lateral } \\
\text { canals }\end{array}$} & \multirow[t]{3}{*}{$\begin{array}{l}\text { Velocity } \\
\text { regression }\end{array}$} & Right & & 4.203 & 0.240 & $\begin{array}{l}\text { The differences are } \\
\text { not significant } \\
\text { between operators }\end{array}$ & - & - & 0.067 \\
\hline & & Left & 5.623 & & 0.002 & $\begin{array}{l}\text { The differences are } \\
\text { significant between } \\
\text { operators }\end{array}$ & $\begin{array}{l}1-4 \\
2-4\end{array}$ & $\begin{array}{l}0.002 \\
0.012\end{array}$ & 0.219 \\
\hline & & $\begin{array}{l}\text { Gain } \\
\text { asymmetry }\end{array}$ & & 6.234 & 0.101 & $\begin{array}{l}\text { The differences are } \\
\text { not significant } \\
\text { between operators }\end{array}$ & - & - & 0.099 \\
\hline & \multirow[t]{2}{*}{$\begin{array}{l}40 \mathrm{~ms} \\
\text { median } \\
\text { gain }\end{array}$} & Right & & 10.383 & 0.016 & $\begin{array}{l}\text { The differences are } \\
\text { significant between } \\
\text { operators }\end{array}$ & $3-4$ & 0.002 & 0.165 \\
\hline & & Left & & 22.150 & $<0.001$ & $\begin{array}{l}\text { The differences are } \\
\text { significant between } \\
\text { operators }\end{array}$ & $\begin{array}{l}1-3 \\
2-4 \\
3-4\end{array}$ & $\begin{array}{l}0.007 \\
<0.001 \\
<0.001\end{array}$ & 0.352 \\
\hline & \multirow[t]{2}{*}{$\begin{array}{l}60 \mathrm{~ms} \\
\text { median } \\
\text { gain }\end{array}$} & Right & & 8.444 & 0.038 & $\begin{array}{l}\text { The differences are } \\
\text { significant between } \\
\text { operators }\end{array}$ & $1-3$ & 0.005 & 0.134 \\
\hline & & Left & & 11.957 & 0.008 & $\begin{array}{l}\text { The differences are } \\
\text { significant between } \\
\text { operators }\end{array}$ & $\begin{array}{l}2-4 \\
3-4\end{array}$ & $\begin{array}{l}0.007 \\
0.007\end{array}$ & 0.190 \\
\hline & \multirow[t]{2}{*}{$\begin{array}{l}80 \text { ms } \\
\text { median } \\
\text { gain }\end{array}$} & Right & & 16.617 & 0.001 & $\begin{array}{l}\text { The differences are } \\
\text { significant between } \\
\text { operators }\end{array}$ & $\begin{array}{l}1-2 \\
1-4\end{array}$ & $\begin{array}{l}0.001 \\
<0.001\end{array}$ & 0.264 \\
\hline & & Left & 0.786 & & 0.507 & $\begin{array}{l}\text { The differences are } \\
\text { not significant } \\
\text { between operators }\end{array}$ & - & - & 0.038 \\
\hline \multirow[t]{4}{*}{$\begin{array}{l}\text { Vertical } \\
\text { canals }\end{array}$} & \multirow[t]{4}{*}{$\begin{array}{l}\text { Velocity } \\
\text { regression }\end{array}$} & $\begin{array}{l}\text { Right } \\
\text { anterior }\end{array}$ & 8.713 & & $<0.001$ & $\begin{array}{l}\text { The differences are } \\
\text { significant between } \\
\text { operators }\end{array}$ & $\begin{array}{l}1-2 \\
1-3 \\
1-4\end{array}$ & $\begin{array}{l}<0.001 \\
<0.001 \\
<0.001\end{array}$ & 0.303 \\
\hline & & $\begin{array}{l}\text { Left } \\
\text { posterior }\end{array}$ & & 23.798 & $<0.001$ & $\begin{array}{l}\text { The differences are } \\
\text { significant between } \\
\text { operators }\end{array}$ & $\begin{array}{l}1-2 \\
1-3\end{array}$ & $\begin{array}{l}<0.001 \\
<0.001\end{array}$ & 0.378 \\
\hline & & $\begin{array}{l}\text { Right } \\
\text { posterior }\end{array}$ & 0.665 & & 0.577 & $\begin{array}{l}\text { The differences are } \\
\text { not significant } \\
\text { between operators }\end{array}$ & - & - & 0.032 \\
\hline & & $\begin{array}{l}\text { Left } \\
\text { anterior }\end{array}$ & 0.552 & & 0.649 & $\begin{array}{l}\text { The differences are } \\
\text { not significant } \\
\text { between operators }\end{array}$ & - & - & 0.027 \\
\hline
\end{tabular}

the vHIT test should be performed by experienced examiners. ${ }^{12,13,31,32}$ However, there is not enough study as to how experienced the examiner should be and to what extent the results vary among the examiners. In a study comparing the results of an experienced and an inexperienced examiner, no significant difference was found between the examiners in terms of VOR gain deviants. ${ }^{33}$ In another study, vHIT findings of four experienced examiners in cochlear implant users were compared to each other. It was found that there were modest differences in gain values among examiners. However, only lateral canal parameters were used in that study and the experience of the examiners was not mentioned. ${ }^{31}$ In the current study, the clinical experiences of the examiners were kept similar, the same hand-holding technique was used, healthy participants were tested so that the effect of experience, application technique, and the factors of the participant were tried to be excluded, and thus existence of differences of the practitioner on the results were investigated. In addition, the number of examiners compared with the studies in the literature is higher, the evaluation of all semicircular canals and the hand dominance research distinguishes this study from other studies.

Limitations of the study are as follows. The sample size of the current study is small. A greater consistency in data could be obtained by increasing the number of participants. However, it was not possible for the four audiologists to work 
together for additional hours, which would be required by greater sample size. Given that the study included only healthy participants, the corrective saccades could not be evaluated. In the future, additional studies should be conducted to compare the findings of more than two clinicians in patients with vestibular disorders. Finally, as each clinician tested each participant only once, the intra-examiner consistency and fatigue of the participant could not be evaluated.

\section{Conclusion}

The inter-examiner differences of the VOR gain values for the vHIT were statistically significant. For the sake of more reliable vHIT results it could have been more effective if tests had been performed by experienced and skilled clinicians. The serial vHIT testing should be performed by the same examiner to reduce the inter-examiner variability.

\section{Conflict of Interest}

None.

\section{References}

1 Kroenke K, Price RK. Symptoms in the community. Prevalence, classification, and psychiatric comorbidity. Arch Intern Med 1993;153(21):2474-2480

2 Neuhauser HK, von Brevern M, Radtke A, et al. Epidemiology of vestibular vertigo: a neurotologic survey of the general population. Neurology 2005;65(06):898-904

3 Radtke A, Lempert T, Gresty MA, Brookes GB, Bronstein AM, Neuhauser $\mathrm{H}$. Migraine and Ménière's disease: is there a link? Neurology 2002;59(11):1700-1704

4 Ahmed MFM. Rotational chair testing in patients with unilateral peripheral vestibular disorders. Egypt J Otolaryngol 2015;31(02): 115-121

5 Barin K. Background and Technique of Caloric Testing. In: Jacobson GP, Shepard NT, eds. Balance Function Assessment and Management. 2nd ed. San Diego, CA: Plural Publishing; 2016:283-319

6 Cullen KE, Roy JE. Signal processing in the vestibular system during active versus passive head movements. J Neurophysiol 2005;93:1820-1820

7 Halmagyi GM, Curthoys IS. A clinical sign of canal paresis. Arch Neurol 1988;45(07):737-739

8 Weber KP, MacDougall HG, Halmagyi GM, Curthoys IS. Impulsive testing of semicircular-canal function using video-oculography. Ann N Y Acad Sci 2009;1164:486-491

9 Wong AM, Sharpe JA, Tweed D. The vestibulo-ocular reflex in fourth nerve palsy: deficits and adaptation. Vision Res 2002;42 (18):2205-2218

10 Alhabib SF, Saliba I. Video head impulse test: a review of the literature. Eur Arch Otorhinolaryngol 2017;274(03):1215-1222

11 MacDougall HG, Weber KP, McGarvie LA, Halmagyi GM, Curthoys IS. The video head impulse test: diagnostic accuracy in peripheral vestibulopathy. Neurology 2009;73(14):1134-1141

12 Macdougall HG, McGarvie LA, Halmagyi GM, Curthoys IS, Weber KP. The video head impulse test (vHIT) detects vertical semicircular canal dysfunction. PLoS One 2013;8(04):e61488

13 MacDougall HG, McGarvie LA, Halmagyi GM, Curthoys IS, Weber KP. Application of the video head impulse test to detect vertical semicircular canal dysfunction. Otol Neurotol 2013;34(06):974-979

14 Ross LM, Helminski JO. Test-retest and interrater reliability of the video head impulse test in the pediatric population. Otol Neurotol 2016;37(05):558-563
15 McCaslin DL, Jacobson GP, Bennett ML, Gruenwald JM, Green AP. Predictive properties of the video head impulse test: measures of caloric symmetry and self-report dizziness handicap. Ear Hear 2014;35(05):e185-e191

16 Bartl K, Lehnen N, Kohlbecher S, Schneider E. Head impulse testing using video-oculography. Ann N Y Acad Sci 2009;1164 (01):331-333

17 Patterson JN, Bassett AM, Mollak CM, Honaker JA. Effects of hand placement technique on the video head impulse test (vHIT) in younger and older adults. Otol Neurotol 2015;36(06):1061-1068

18 Suh M-W, Park JH, Kang SI, Lim JH, Park MK, Kwon SK. Effect of goggle slippage on the video head impulse test outcome and its mechanisms. Otol Neurotol 2017;38(01):102-109

19 Curthoys IS, Macdougall HG, McGarvie LA, et al. The video head impulse test (vHIT). In: Jacobson GP, Shepard NT, eds. Balance Function Assessment and Management. 2nd ed. San Diego, CA: Plural Publishing; 2016:391-430

20 Blödow A, Blödow J, Bloching MB, Helbig R, Walther LE. Horizontal VOR function shows frequency dynamics in vestibular schwannoma. Eur Arch Otorhinolaryngol 2015;272(09):2143-2148

21 Koo TK, Li MY. A guideline of selecting and reporting intraclass correlation coefficients for reliability research. J Chiropr Med 2016;15(02):155-163

22 Ahadi M, Rezazadeh N, Pourbakht A. Comparison of vestibuloocular reflex instantaneous gain and velocity regression in differentiating the peripheral vestibular disorders. Aud Vest Res 2017;26(04):195-201

23 Blödow A, Helbig R, Wichmann N, Bloching M, Walther LE. The video head impulse test: first clinical experiences [in German]. HNO 2013;61(04):327-334

24 Blödow A, Helbig R, Wichmann N, Wenzel A, Walther LE, Bloching $\mathrm{MB}$. Video head impulse test or caloric irrigation? Contemporary diagnostic tests for vestibular schwannoma [in German]. HNO 2013;61(09):781-785

25 Naderi N, Hajiabolhassan F, Farahani S, Yazdani N, Jalaie S. Normative vestibulo-ocular reflex data in yaw and pitch axes using the video head-impulse test. Aud Vest Res 2016;25(01):39-48

26 Hirvonen M, Aalto H, Migliaccio AA, Hirvonen TP. Motorized head impulse rotator for horizontal vestibulo-ocular reflex: normal responses. Arch Otolaryngol Head Neck Surg 2007;133(02): 157-161

27 Wiener-Vacher SR, Wiener SI. Video head impulse tests with a remote camera system: normative values of semicircular canal vestibulo-ocular reflex gain in infants and children. Front Neurol 2017;8(434):434

28 Bansal S, Sinha SK. Assessment of VOR gain function and its testretest reliability in normal hearing individuals. Eur Arch Otorhinolaryngol 2016;273(10):3167-3173

29 McGarvie LA, MacDougall HG, Halmagyi GM, Burgess AM, Weber $\mathrm{KP}$, Curthoys IS. The video head impulse test (vHIT) of semicircular canal function-age-dependent normative values of VOR gain in healthy subjects. Front Neurol 2015;6:154

30 Murnane O, Mabrey H, Pearson A, Byrd S, Akin F. Normative data and test-retest reliability of the SYNAPSYS video head impulse test. J Am Acad Audiol 2014;25(03):244-252

31 Korsager LEH, Schmidt JH, Faber C, Wanscher JH. Reliability and comparison of gain values with occurrence of saccades in the EyeSeeCam video head impulse test (vHIT). Eur Arch Otorhinolaryngol 2016;273(12):4273-4279

32 Weber KP, MacDougall HG, McGarvie LA, et al. The video head impulse test: diagnostic accuracy in peripheral vestibulopathy. Neurology 2010;74:A386

33 Jacobsen CL, Abrahamsen ER, Skals RK, Hougaard DD. Is Regression Gain or Instantaneous Gain the most reliable and reproducible gain value when performing video Head Impulse Testing of the lateral semicircular canals? In 31st Politzer Society Meeting \& 2nd Global Otology Research Forum; 2018 